\title{
Assessing heavy metal pollution and potential ecological risk of tea plantation soils
}

\author{
Zuoping Zhao ${ }^{1,2,3}$, Sha Yan ${ }^{1}$, Min Duan ${ }^{4}$, Jing Fu ${ }^{1}$, Qi Wang ${ }^{1}$, Zhifeng Liu ${ }^{1,3}$, \\ Fengmin Song ${ }^{1,3}$, Bo Tang ${ }^{1,3}$, Chen $\mathrm{Li}^{1,3}$, Gongwei Qin ${ }^{1}$, Yanan Tong ${ }^{5 *}$ \\ (1. Shaanxi University of Technology, Hanzhong 723001, Shaanxi, China; \\ 2. Key Laboratory for Agricultural Environment, Ministry of Agriculture and Rural Affairs, Beijing, 100081, China; \\ 3. Shaanxi Key Laboratory of Catalysis, Hanzhong 723001, Shaanxi, China; \\ 4. College of Life Sciences, Guangxi Normal University, Guilin 541004, Guangxi, China; \\ 5. College of Natural Resources and Environment, Northwest A\&F University, Yangling 712100, Shaanxi, China)
}

\begin{abstract}
Accumulation of heavy metals in agricultural soils tends to increase crop uptake of heavy metals, and can adversely impact human health through food chains. This study assessed the heavy metal pollution status and the potential ecological risk of tea plantation soils in southern Shaanxi Province, China. A total of 330 topsoil samples were collected to analyze the concentrations of seven heavy metals $(\mathrm{Pb}, \mathrm{Zn}, \mathrm{Cu}, \mathrm{Cr}, \mathrm{Hg}, \mathrm{As}$ and $\mathrm{Cd})$ and the $\mathrm{pH}$ level. The Hakanson potential ecological risk index was used based on the background levels of soil heavy metals in Shaanxi. Results showed that the averaged concentrations of soil $\mathrm{Pb}, \mathrm{Zn}, \mathrm{Cu}, \mathrm{Cr}, \mathrm{Hg}$, As, and $\mathrm{Cd}$ were 10.0, 87.6, 16.4, 12.4, 0.2, 6.9 and $0.1 \mathrm{mg} / \mathrm{kg}$, respectively. Cd and Hg concentrations exceeded level II of China's Soil Environment Quality Standard (GB 15618-2009) in 9.3\% and 7.0\% of the total samples, respectively. The coefficient of variation ranged from $29.2 \%$ to $52.2 \%$ for different elements, and was $49.3 \%$ for $\mathrm{Cd}$ and $48.6 \%$ for $\mathrm{Hg}$. The averaged comprehensive potential ecological risk index was 95.4 , and the overall potential ecological risk was low, with $82.4 \%$ of the total samples at a low level of potential ecological risk. $\mathrm{Cd}$ and $\mathrm{Hg}$ contributed most to the potential ecological risk (35.5\% and $46.5 \%$, respectively), and the risks associated with other elements were relatively minor. This study suggested that soil $\mathrm{Cd}$ and $\mathrm{Hg}$ pollution should be controlled to ensure the safe production of tea in the study area.
\end{abstract}

Keywords: ecological risk, heavy metal, soil pollution, tea plantation

DOI: $10.25165 /$ j.ijabe.20191206.4363

Citation: Zhao Z P, Yan S, Duan M, Fu J, Wang Q, Liu Z F, et al. Assessing heavy metal pollution and potential ecological risk of tea plantation soils. Int J Agric \& Biol Eng, 2019; 12(6): 185-191.

\section{Introduction}

In recent decades, urban and rural planning process has accelerated, while industry and agriculture have developed rapidly. Consequently, there has been increasingly environmental pollution caused by the emissions of industrial 'three wastes' (waste gas, waste water and waste residue), overexploitation of mining

\section{Received date: $2018-05-12 \quad$ Accepted date: 2019-10-13}

Biographies: Zuoping Zhao, PhD, Associate Professor, research interests: environmental pollution control, Email: zhaozuoping@126.com; Sha Yan, Lecturer, research interests: ecological mathematical model, Email: Yansha6688@126.com; Min Duan, PhD, Associate Professor, research interests soil carbon cycling greenhouse gas emissions land reclamation, Email: duanmin0517@163.com; Jing Fu, PhD, research interest: food safety, Email: 18740661182@139.com; Qi Wang, Associate Professor, research interests: phytobiology, Email: wangqis6@163.com; Zhifeng Liu, Associate Professor, research interests: soil microbiology, Email: 1zhifeng2005@163.com; Fengmin Song, Associate Professor, research interests: environmental pollution restoration, Email: sfm3297@163.com; Bo Tang, Associate Professor, research interests: environmental pollution restoration, Email: xiaotang1219czh@, yahoo.com.cn; Chen Li, Associate Professor, research interests: pollution abatement, Email: myworkspace1980@126.com; Gongwei Qin, Associate Professor, research interests: blueberry cultivation techniques, Email: slg357@snut.edu.cn.

*Corresponding author: Yanan Tong, Professor, Doctoral supervisor, research interests: plant nutrition. College of Natural Resources and Environment, Northwest A\&F University, Yangling 712100, Shaanxi, China. Email: tongyanan@nwsuaf.edu.cn. resources, extensive application of chemical fertilizers, and automobile exhaust emissions. In particular, problems resulted from soil heavy metal pollution have drawn widespread attention from researchers ${ }^{[1-3]}$. The area of arable land subjected to heavy metal pollution has reached more than $2000 \mathrm{hm}^{2}$ in China, accounting for about $20 \%$ of the total arable land in the country; the annual output of grains polluted by heavy metals is up to 12 million tons, resulting in an economic loss of more than $\$ 12.4$ billion $^{[4]}$.

Unlike other pollution, soil heavy metal pollution is cumulative, complex, concealed, irreversible, hysteretic, and severe. Once heavy metals enter the soil environment, they can accumulate in agricultural products and endanger human health through food chains ${ }^{[5]}$. Thus, assessment of soil heavy metal pollution and the ecological risk in agricultural areas have become increasingly important. In recent years, numerous studies have been conducted to assess heavy metal levels and soil quality in vegetable-producing $\operatorname{areas}^{[6,7]}$, farmlands ${ }^{[8-10]}$, production areas of economic crops ${ }^{[11,12]}$, and wastewater irrigation and mining areas ${ }^{[13,14]}$.

Since the health benefits of drinking tea have been recognized ${ }^{[15]}$, the soil environmental quality in tea plantations has begun to receive more attention. Previous studies in tea plantations have focused on the investigation of soil fertility and physicochemistry, and the influence of beneficial trace metals on tea quality ${ }^{[16,17]}$. As soil heavy metal pollution became increasingly prominent, there has been growing concern about its effects in tea plantations ${ }^{[18-20]}$. Chen et al. ${ }^{[1]}$ found that tea trees, 
which are perennial evergreen plants, have greater ability to enrich heavy metals in the soil and higher sensitivity to pollutants compared with other plants under the same conditions. Heavy metals in tea plantation soils have low leach ability and are difficult to be degraded by microbes; thus, they often accumulate in tea plantation soils and can be transformed into methyl compounds, which have a greater toxicity ${ }^{[22]}$.

Soil heavy metal pollution in tea plantations is mainly due to agricultural production, extensive use of fertilizers and pesticides, and application of organic sludge and manure. $\mathrm{Wu}$ et al. ${ }^{[23]}$ showed that long-term use of fertilizers and pesticides led to different degrees of $\mathrm{Ni}$ pollution in tea plantation soils and increased $\mathrm{Ni}$ concentration in tea through root absorption. Shi et al. ${ }^{[24]}$ showed that $\mathrm{Cd}$ and As concentrations almost doubled in tea over the past 10 years, mainly due to extensive application of chemical fertilizers and pesticides. Michael et al. ${ }^{[25]}$ found that there was a linear correlation between heavy metal concentrations in tea plantation soils and tea. As tea plants are used to produce beverages for human consumption, there is a high possibility of extracting pollutants by continuous soaking of tea leaves from polluted tea plantation soils, which poses a potential threat to human health. Therefore, soil heavy metal pollution of tea plants appears to be more important than that in other plants.

Shaanxi Province is the largest tea-planting area in Northwestern China, with a tea plantation area of $143900 \mathrm{hm}^{2}$, accounting for $5 \%$ of the total tea plantation area in China. In the past five years, Shaanxi was one of the provinces that had highest increase of tea plantation area in the country. The tea plantations are mainly located in southern Shaanxi, where tea plantation and production have become a major industry for local farmers to overcome poverty and protect the ecological environment. However, during the development of tea plantations, few studies have systemically investigated the tea-growing environment in this region.

In the present study, soils were collected from the major tea-growing areas in southern Shaanxi and the Hakanson potential ecological risk index was used to assess heavy metal pollution and the ecological risk of tea plantation soil. This study provides reference data for pollution-free cultivation, early warning of ecology risk, and the safe production of tea in southern Shaanxi.

\section{Materials and methods}

\subsection{Study area}

The study area is located in Hanzhong Basin (106 $51^{\prime}$ $108^{\circ} 05^{\prime} \mathrm{E}, 32^{\circ} 12^{\prime}-33^{\circ} 15^{\prime} \mathrm{N}$ ), the main tea-growing area of southern Shaanxi, China. The topography ranges from flat to hilly to mountainous, with low elevation in the south and high elevation in the north. The flat areas are usually 500-600 $\mathrm{m}$ above sea level, with flatterrain and fertile soil, accounting for $34.6 \%$ of the total area. The hilly areas are $600-800 \mathrm{~m}$ above sea level, with a large relief, accounting for about $28.1 \%$ of the total area. The remaining $37.2 \%$ of the area consists of mountains, with complex terrain and poor soil, between 700-2038 m above sea level.

The area is located in a warm sub-humid zone with a northern subtropical monsoon climate. The annual average temperature ranges from $12^{\circ} \mathrm{C}$ to $16^{\circ} \mathrm{C}$ and the annual average precipitation is between 700-1800 mm. The Qinling Mountain blocks cold air from the north, resulting in a warm and humid climate; hence, this region has one of the largest tea-planting areas in Shaanxi Province. This is a representative area for investigating the present soil heavy metal pollution status in tea plantations.

\subsection{Soil sampling}

Eight tea-growing areas were selected in Hanzhong Basin: Xixiang, Ningqiang, Nanzheng, Mianxian, Zhenba, Chenggu, Yangxian, and Lueyang. The number and distribution of soil sampling sites were determined based on the total tea plantation area in the eight selected areas and the location of the sampling sites in the second soil census.

A total of 330 soil samples $(0-30 \mathrm{~cm})$ were selected from 33 tea plantations (T1-T33) in the eight tea-growing areas (Figure 1). The GPS instrument was used for accurate positioning. Soil samples were collected in an S-shaped pattern and every five samples from the same plot were mixed to form a composite sample. The samples were transported to the laboratory, dried to remove weeds, crop residues, and gravel. All samples were grounded using an agate mortar and passed through 20 mesh and 100 mesh nylon sieves for the analysis of $\mathrm{pH}$ and total heavy metals, respectively.

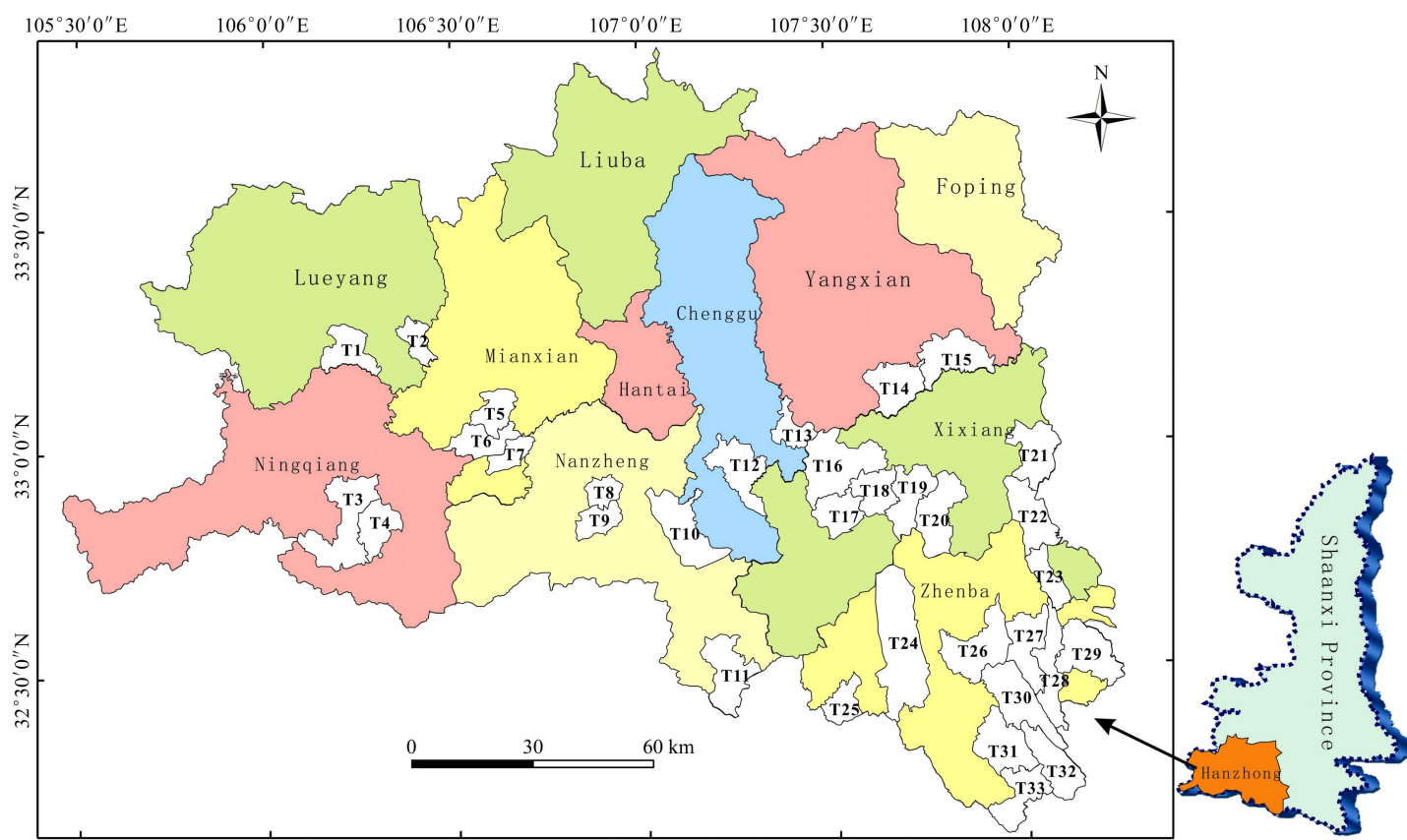

Figure 1 Study area and distribution of the sampling sites in 33 tea plantations (T1-T33) in southern Shaanxi province, China 


\subsection{Sample analysis}

Heavy metals were analyzed using soil samples through 100 mesh sieve. Concentrations of $\mathrm{Pb}, \mathrm{Cu}, \mathrm{Cr}$, and $\mathrm{Zn}$ were determined by flame atomic absorption spectrometry after soil samples were digested with $\mathrm{HNO}_{3}-\mathrm{HClO}_{4}-\mathrm{HF}$. Concentrations of $\mathrm{Cd}$, As, and $\mathrm{Hg}$ were determined by graphite furnace atomic absorption spectrometry after soil samples were digested with $\mathrm{HNO}_{3}-\mathrm{H}_{2} \mathrm{SO}_{4}$. The standard material of GSS-14 was used for quality control and the spiked recoveries were $96.4 \%-101.3 \%$ for $\mathrm{Cr}, 95.9 \%-101.5 \%$ for $\mathrm{Cu}, 96.5 \%-108.2 \%$ for $\mathrm{Pb}, 92.9 \%-100.6 \%$ for $\mathrm{Zn}, 93.2 \%-104.9 \%$ for $\mathrm{Cd}, 93.6 \%-99.8 \%$ for $\mathrm{Hg}$, and $94.3 \%-99.6 \%$ for As. The soil $\mathrm{pH}$ was measured by potentiometry using soil samples through 20 mesh sieve at a soil to water ratio of $1: 5^{[26]}$.

\subsection{Statistical analysis}

One-way analysis of variance (ANOVA) and least significant difference (LSD) multiple comparison were applied to determine the significance of difference between the soil heavy metal concentrations and the national standard or provincial background levels. Before the ANOVA analysis, the normality of distribution and homogeneity of variance were tested. The relationships between soil heavy metal concentrations and $\mathrm{pH}$ were evaluated by Pearson's correlation analysis. A $p$ value of lower than 0.05 was considered statistically significant. All statistical analyses were conducted using the SPSS 13.0 software (SPSS Inc., Chicago, IL, USA).

\subsection{Assessment methods and criteria}

The single factor pollution index and the comprehensive pollution index are commonly used to evaluate soil heavy metal pollution in China ${ }^{[13]}$. However, these methods often use level II of China's Soil Environment Quality Standard as the assessment criteria. As the soil background levels of heavy metals vary across different regions, there may be a risk of pollution in some areas with low soil background level based on the national standard, although the critical value for heavy metal pollution is not reached after years of accumulation.

Herein, the Hakanson potential ecological risk index was used for assessment of soil pollution risk in tea plantations based on the background levels of soil heavy metals in Shaanxi Province. This index was put forward by Hakanson from Switzerland, mainly for the potential ecological risk assessment of soil heavy metals. It gives comprehensive consideration to the concentration, toxicity, ecological sensitivity, and synergy of multi-elements ${ }^{[27,28]}$. The index is calculated as follows:

$$
\begin{aligned}
& C_{f}^{i}=C_{s}^{i} / C_{n}^{i} \\
& C_{d}=\sum C_{f}^{i} \\
& E_{r}^{i}=T_{r}^{i} C_{f}^{i} \\
& I_{\mathrm{R}}=\sum E_{r}^{i}
\end{aligned}
$$

where, $C_{f}^{i}$ is the single factor pollution index of the $i$ th heavy metal; $C_{s}^{i}$ is the measured level of the $i$ th heavy metal; $C_{n}^{i}$ is the background level of the $i$ th heavy metal, $C_{d}=\sum C_{f}^{i}$ is the sum of the pollution index of multiple heavy metals; $E_{r}^{i}$ is the potential ecological risk factor of a single heavy metal; $T_{r}^{i}$ is the toxic response factor of the $i$ th heavy metal, and $I_{R}$ is the comprehensive potential ecological risk factor of multiple heavy metals.

The toxic response factors of the seven heavy metals tested were ranked as $\mathrm{Hg}(40)>\mathrm{Cd}(30)>\mathrm{As}(10)>\mathrm{Cu}(5)=\mathrm{Pb}(5)>\mathrm{Cr}$
(2) $>$ Zn $(1)^{[13,28]}$. The potential ecological risk factor of a single heavy metal was classified as follows: $E_{r}^{i}<40$, low pollution; $40 \leq E_{r}^{i}<80$, moderate pollution; $80 \leq E_{r}^{i}<160$, high pollution; $160 \leq E_{r}^{i}<320$, very high pollution; $E_{r}^{i} \geq 320$, extremely high pollution. The comprehensive potential ecological risk factor of multiple heavy metals was classified as follows: $I_{R}<150$, low pollution, $150 \leq I_{R}<300$, moderate pollution; $300 \leq I_{R}<600$, high pollution; $I_{R} \geq 600$, very high pollution.

\section{Results}

\subsection{Characteristics of soil heavy metal concentrations}

The descriptive statistics of the concentrations of the seven heavy metals in the 330 soil samples are shown in Table 1 . The pollution assessment was performed using level II of China's Soil Environment Quality Standard ${ }^{[29]}$, and the cumulative potential of heavy metals was analyzed using the soil background levels in Shaanxi.

There were significant differences in the concentrations of various heavy metals in the tea plantation soils in southern Shaanxi: 2.4-29.2 mg/kg for $\mathrm{Pb}, 25.7-46.9 \mathrm{mg} / \mathrm{kg}$ for $\mathrm{Zn}, 7.5-29.0 \mathrm{mg} / \mathrm{kg}$ for $\mathrm{Cu}, 0.8-27.8 \mathrm{mg} / \mathrm{kg}$ for $\mathrm{Cr}, 0.08-0.38 \mathrm{mg} / \mathrm{kg}$ for $\mathrm{Hg}, 2.1-13.9 \mathrm{mg} / \mathrm{kg}$ for As, and $0.03-0.33 \mathrm{mg} / \mathrm{kg}$ for $\mathrm{Cd}$. The $\mathrm{Cd}$ and $\mathrm{Hg}$ concentrations in some samples $(9.3 \%$ and $6.9 \%$ of the total samples, respectively) were higher than the level II national standard, which indicates $\mathrm{Hg}$ and $\mathrm{Cd}$ pollution in tea plantation soils of the sampling areas. The concentrations of the remaining five heavy metals $(\mathrm{Pb}, \mathrm{Zn}, \mathrm{Cu}, \mathrm{Cr}$, and $\mathrm{As})$ did not exceed the level II national standard, which indicates that the study area was not polluted by these five heavy metals. The mean concentrations of the seven heavy metals did not exceed the level II national standard.

Table 1 Summary statistics of heavy metal concentrations in the topsoil from tea plantations in the study area

\begin{tabular}{lccccccc}
\hline \multicolumn{1}{c}{ Heavy metal/mg $\mathrm{kg}^{-1}$} & $\mathrm{~Pb}$ & $\mathrm{Zn}$ & $\mathrm{Cu}$ & $\mathrm{Cr}$ & $\mathrm{Hg}$ & $\mathrm{As}$ & $\mathrm{Cd}$ \\
\hline Maximum & 29.2 & 146.9 & 29.0 & 27.8 & 0.38 & 13.9 & 0.33 \\
Minimum & 2.4 & 25.7 & 7.5 & 0.8 & 0.08 & 2.3 & 0.03 \\
Mean & 10.1 & 87.6 & 16.4 & 12.4 & 0.20 & 6.9 & 0.11 \\
Coefficient of variation/\% & 37.4 & 37.4 & 29.1 & 45.9 & 48.6 & 52.2 & 49.3 \\
Standard deviation & 3.75 & 32.79 & 4.79 & 5.69 & 0.10 & 3.60 & 0.07 \\
Provincial background level $\dagger$ & 20.9 & 69.4 & 19.5 & 61.1 & 0.18 & 6.4 & 0.09 \\
Permitted maximum level $\ddagger$ & 250 & 200 & 50 & 250 & 0.30 & 30 & 0.30 \\
pH 6.5-7.5 & 300 & 250 & 100 & 300 & 0.50 & 25 & 0.60 \\
pH $>$ 7.5 & 350 & 300 & 100 & 350 & 1.00 & 20 & 1.00 \\
\hline
\end{tabular}

Note: $\uparrow$ Soil background levels of heavy metals in Shaanxi province, $\mathrm{China}^{[13]}$; + Level II China's Soil Environment Quality Standard (GB15618-2009) ${ }^{[29]}$.

Compared with the provincial background levels, the maximum concentrations of $\mathrm{Pb}$ and $\mathrm{Cu}$ were higher, but their mean concentrations were lower. In addition, the mean concentrations of $\mathrm{Zn}, \mathrm{Hg}$, As, and $\mathrm{Cd}$ were higher than the provincial background levels. This indicated that the six heavy metals have accumulated to a certain extent in tea plantation soils in the study area. In particular, the mean concentrations of $\mathrm{Zn}, \mathrm{Hg}$, As, and $\mathrm{Cd}$ were $1.26,1.11,1.07$, and 1.11 times as much as the provincial background levels. However, according to the frequency distribution (Figure 2), the frequencies of $\mathrm{Cd}, \mathrm{Hg}, \mathrm{Pb}, \mathrm{Cu}, \mathrm{Zn}$, and As concentrations that exceeding the provincial background levels were $41.2 \%, 35.3 \%, 15.7 \%, 19.6 \%, 43.1 \%$ and $27.5 \%$, respectively. These results indicated that in the tea-growing environment, 
external factors such as human activities have led to an increase in soil heavy metal concentrations, with greater accumulation of $\mathrm{Zn}$, $\mathrm{Cd}$, and $\mathrm{Hg}$.
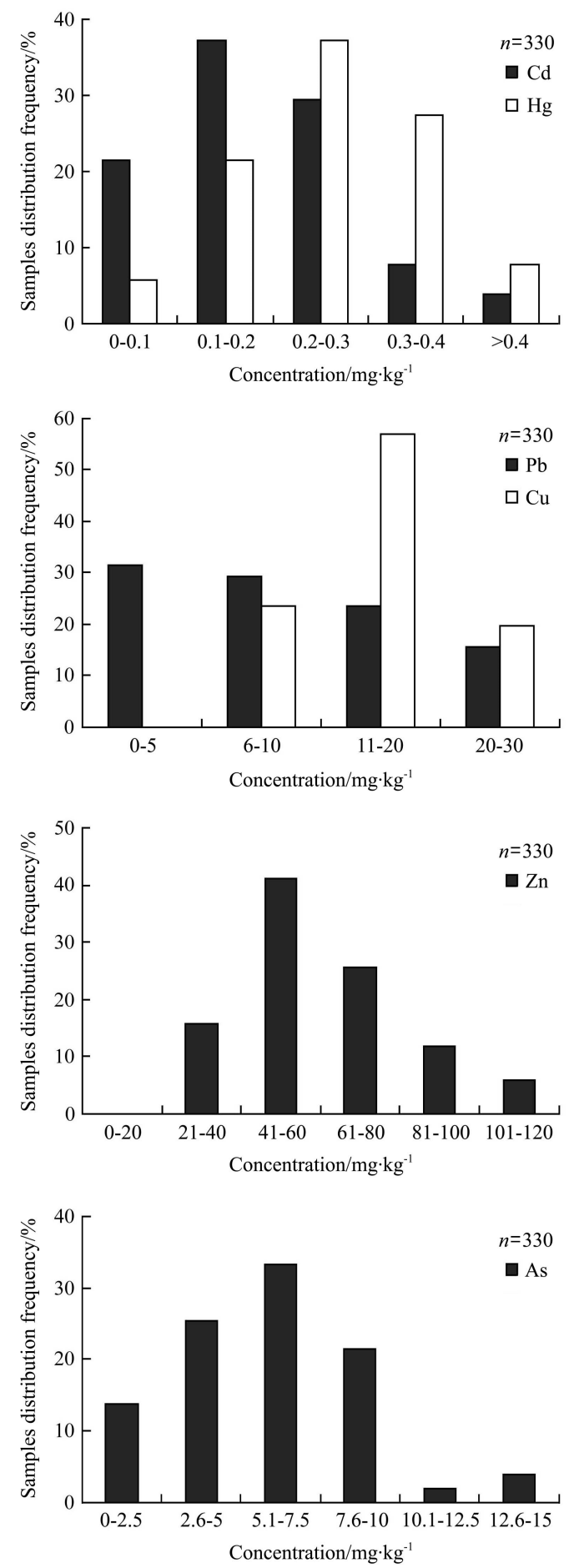

Figure 2 Frequency histograms of heavy metal concentrations in tea plantation soils

The difference in the regional distribution and pollution degree of heavy metals can be reflected by the coefficient of variation $(\mathrm{CV})$. Higher $C V$ value usually led to greater difference of the sampling site compared with the overall study area ${ }^{[30,31]}$. The $C V$ values of the seven heavy metals in tea plantation soils ranked as As $>\mathrm{Cd}>\mathrm{Hg}>\mathrm{Cr}>\mathrm{Zn}>\mathrm{Pb}>\mathrm{Cu}$ (Table 1). The $C V$ values of As, $\mathrm{Cd}, \mathrm{Hg}, \mathrm{Cr}, \mathrm{Zn}$, and $\mathrm{Pb}$ were greater than $30 \%$. In particular, the $\mathrm{CV}$ values of $\mathrm{As}, \mathrm{Cd}$, and $\mathrm{Hg}$ were up to $52.2 \%, 49.3 \%$, and $48.6 \%$, respectively, indicating a large difference in the distribution of these three elements across the study area. The $C V$ values of $\mathrm{Pb}$ and $\mathrm{Zn}$ were between $30 \%$ and $40 \%$, suggesting a similar degree of pollution. The $C V$ value of $\mathrm{Cu}$ was $29.1 \%(<30 \%)$, indicating a relatively uniform spatial distribution of this element.

\subsection{Correlations between soil heavy metal concentrations and pH}

Correlations were found between the concentrations of most heavy metals tested in tea plantation soils in southern Shaanxi (Table 2). The correlation coefficients between $\mathrm{Cd}$ and $\mathrm{Pb}, \mathrm{Hg}$, and As concentrations were greater than $0.224(p<0.01) . \quad \mathrm{Cd}$ and $\mathrm{Zn}$ had correlation coefficient of $0.139(p<0.05)$. The correlation coefficients between $\mathrm{Cu}$ and $\mathrm{Cr}$ and $\mathrm{Zn}$ were 0.638 and 0.482 , respectively $(p<0.01)$. The correlation between $\mathrm{Pb}$ and $\mathrm{Hg}$ and $\mathrm{Zn}$ was also significant, with the value of 0.235 and 0.348 , respectively $(p<0.01)$. The correlation between $\mathrm{Cr}$ and $\mathrm{Zn}$ was $0.399(p<0.01)$. These results suggest that soil $\mathrm{Cd}, \mathrm{Pb}, \mathrm{Hg}$, and As have similar origins, therefore they accumulated simultaneously and caused combined pollution in the study area. The correlations between soil $\mathrm{Cu}, \mathrm{Cr}$, and $\mathrm{Zn}$ were also significant, these three elements might also have similar origins.

The correlation analysis showed that the correlation coefficients between $\mathrm{pH}$ and $\mathrm{Cd}$ and $\mathrm{Cu}$ were 0.275 and 0.354 , respectively $(p<0.01)$.No significant correlations were found between $\mathrm{pH}$ and the other five elements (Table 2).

Table 2 Pearson's correlation coefficient between heavy metal concentrations and $\mathrm{pH}$ of tea plantation soils in southern

Shaanxi, China

\begin{tabular}{ccccccccc}
\hline Heavy metal & $\mathrm{Cd}$ & $\mathrm{Cu}$ & $\mathrm{Pb}$ & $\mathrm{Cr}$ & $\mathrm{Hg}$ & $\mathrm{As}$ & $\mathrm{Zn}$ & $\mathrm{pH}$ \\
\hline $\mathrm{Cd}$ & 1.000 & & & & & & & \\
$\mathrm{Cu}$ & -0.057 & 1.000 & & & & & & \\
$\mathrm{~Pb}$ & $0.319^{* *}$ & -0.133 & 1.000 & & & & & \\
$\mathrm{Cr}$ & -0.083 & $0.638^{* *}$ & 0.037 & 1.000 & & & & \\
$\mathrm{Hg}$ & $0.858^{* *}$ & -0.042 & $0.235^{* *}$ & -0.093 & 1.000 & & & \\
$\mathrm{As}$ & $0.865^{* *}$ & -0.092 & 0.037 & -0.144 & $0.795^{* *}$ & 1.000 & & \\
$\mathrm{Zn}$ & $0.139^{*}$ & $0.482^{* *}$ & $0.348^{* *}$ & $0.399^{* *}$ & 0.061 & 0.015 & 1.000 & \\
$\mathrm{pH}$ & $0.275^{* *}$ & $0.354^{* *}$ & -0.254 & -0.092 & 0.092 & -0.157 & -0.017 & 1.000 \\
\hline
\end{tabular}

Note: ${ }^{*} p<0.05$ and ${ }^{* *} p<0.01$.

\subsection{Potential ecological risk assessment of soil heavy metal pollution}

The ranges of the Hakanson potential ecological risk index for a single heavy metal were obtained: $0-103.7$ for $\mathrm{Cd}, 1.927 .44$ for $\mathrm{Cu}, 0-6.97$ for $\mathrm{Pb}, 0.030 .91$ for $\mathrm{Cr}, 17.6783 .97$ for $\mathrm{Hg}, 3.58-21.76$ for As and 0.37-2.11 for $\mathrm{Zn}$. The means of the single index values for $\mathrm{Cd}, \mathrm{Cu}, \mathrm{Pb}, \mathrm{Cr}, \mathrm{Hg}$, As and $\mathrm{Zn}$ were $33.89,4.26,2.32,0.41$, 44.46, 9.37, and 0.83, respectively, ranking as $\mathrm{Hg}>\mathrm{Cd}>\mathrm{As}>\mathrm{Cu}>$ $\mathrm{Pb}>\mathrm{Zn}>\mathrm{Cr}$. Apart from $\mathrm{Hg}$, all the elements had single index values less than 40 . The maximum single index values of $\mathrm{As}, \mathrm{Pb}$, $\mathrm{Cu}, \mathrm{Zn}$, and $\mathrm{Cr}$ were less than 40 , indicating that the sampling areas were exposed to these five heavy metals at a low ecological risk level; these five elements had a lower contribution to the potential ecological risk and generally showed no effect in the tea plantation soils.

Although the mean of the ecological risk index of $\mathrm{Cd}$ was $33.89(<40)$, the range of the index value was wide and the maximum value was 103.7.There were 18 samples with an ecological risk index greater than 80 , which accounted for $5.5 \%$ of the total samples. These 18 samples were mainly distributed in the T2, T5, and T12 sampling areas, indicated a high level of ecological risk for $\mathrm{Cd}$ pollution in these three tea plantations. Meanwhile, $29.1 \%$ of the samples were exposed to a moderate level of ecological risk and $65.5 \%$ of the samples were at a lower 
level of ecological risk for $\mathrm{Cd}$ pollution. The mean of the ecological risk index of $\mathrm{Hg}$ was $44.46(>40)$, and the maximum value reached 83.97. The overall ecological risk analysis of $\mathrm{Hg}$ pollution showed that low and moderate levels of ecological risk were dominant, accounting for $42.4 \%$ and $51.8 \%$ of the total samples, respectively. Only $5.8 \%$ of the samples were exposed to a high level of ecological risk for $\mathrm{Hg}$ pollution, which were mainly distributed in the T5, T6, T8, and T22 sampling areas. $\mathrm{Cd}$ and $\mathrm{Hg}$ contributed $35.5 \%$ and $46.5 \%$, respectively, to the ecological risk of the tea plantation soils. Thus, $\mathrm{Hg}$ and $\mathrm{Cd}$ were the dominant factors in the potential ecological risk of tea plantation soils in southern Shaanxi, contributing $82 \%$ of the total ecological risk.

Table 3 Statistical analysis of the single ecological risk index for soil pollution with heavy metals in tea plantations

\begin{tabular}{|c|c|c|c|c|c|c|c|c|c|}
\hline \multirow{3}{*}{$\begin{array}{l}\text { Heavy } \\
\text { metal }\end{array}$} & \multirow{3}{*}{ Maximum } & \multirow{3}{*}{ Minimum } & \multirow{3}{*}{ Mean } & \multirow{3}{*}{$\begin{array}{l}\text { Standard } \\
\text { deviation }\end{array}$} & \multicolumn{5}{|c|}{ Distribution frequency of samples } \\
\hline & & & & & $E_{r}^{i}<40$ & $40 \leq E_{r}^{i}<80$ & $80 \leq E_{r}^{i}<160$ & $160 \leq E_{r}^{i}<320$ & $E_{r}^{i} \geq 320$ \\
\hline & & & & & Low & Medium & Strong & Very strong & Greatly strong \\
\hline $\mathrm{Cd}$ & 103.70 & 0 & 33.89 & 27.95 & 216 & 96 & 18 & 0 & 0 \\
\hline $\mathrm{Cu}$ & 7.44 & 1.92 & 4.26 & 1.21 & 330 & 0 & 0 & 0 & 0 \\
\hline $\mathrm{Pb}$ & 6.97 & 0 & 2.32 & 2.09 & 330 & 0 & 0 & 0 & 0 \\
\hline $\mathrm{Cr}$ & 0.91 & 0.03 & 0.41 & 0.18 & 330 & 0 & 0 & 0 & 0 \\
\hline $\mathrm{Hg}$ & 83.97 & 17.67 & 44.46 & 20.30 & 140 & 171 & 19 & 0 & 0 \\
\hline As & 21.76 & 3.58 & 9.37 & 4.86 & 330 & 0 & 0 & 0 & 0 \\
\hline $\mathrm{Zn}$ & 2.11 & 0.37 & 0.83 & 0.33 & 330 & 0 & 0 & 0 & 0 \\
\hline
\end{tabular}

The comprehensive potential ecological risk index $\left(I_{R}\right)$ of the seven heavy metals had a maximum of 226.90 and a minimum of 23.58 , with a mean of $95.37(<150)$. This result indicated that the study area has an overall low level of potential ecological risk. Statistical analysis showed that 272 samples $(82.4 \%)$ were at a low level of potential ecological risk, and 58 samples (17.6\%) were at a moderate level of potential ecological risk. This indicated that most of the tea plantation soils have a low level of potential ecological risk for soil heavy metal pollution.

Table 4 Statistical analysis of the potential ecological risk index for soil pollution with heavy metals in tea plantations

\begin{tabular}{ccccc}
\hline Potential ecological risk & $I_{R}<150$ & $150 \leq I_{R}<300$ & $300 \leq I_{R}<600$ & $I_{R} \geq 600$ \\
\hline Degree & Low & Medium & Strong & Very strong \\
Frequency & 272 & 58 & 0 & 0 \\
Percentage & 82.4 & 17.6 & 0 & 0 \\
\hline
\end{tabular}

\section{Discussion}

The single factor pollution index and the Nemerow comprehensive pollution index are the two most commonly used methods to evaluate soil heavy metal pollution ${ }^{[13]}$ based on level II of China's Soil Environment Quality Standard. As the background levels of soil heavy metals vary across regions, the use of a unified standard may result in a risk of pollution in some areas where the threshold for pollution has not been reached after years of accumulation. For example, when the soil $\mathrm{pH}$ is greater than 7.5, the limit of soil $\mathrm{Cr}$ pollution is defined at $350 \mathrm{mg} / \mathrm{kg}$ by the Soil Environment Quality Standard of China. However, a previous study ${ }^{[32]}$ pointed out that a $\mathrm{pH}$ higher than 7 is conducive to the formation of hexavalent chromium and the limit of soil total $\mathrm{Cr}$ for toxicity to plants is $75 \mathrm{mg} / \mathrm{kg}$. Therefore, the critical value of soil $\mathrm{Cr}$ pollution defined by the Soil Environment Quality Standard of China is relatively high. In contrast, the background levels of soil heavy metals in some areas are relatively high and exceed the critical values even without an anthropogenic pollution.

The geoaccumulation index is another commonly used method for the evaluation of soil heavy metal pollution ${ }^{[33]}$. Unlike the above mentioned two indices, the geoaccumulation index is based on local background levels of soil heavy metals, and this method sets a constant based on possible fluctuations of the background levels caused by diagenesis. However, this method is only for evaluating the pollution level of a single heavy metal, does not support comprehensive evaluation of multiple heavy metals. The pollution loading index allows the comprehensive pollution load of multiple heavy metals and the regional pollution load in soils to be assessed, but it is not suitable for the evaluation of soil heavy metal pollution with low concentrations and toxicity of heavy metal ${ }^{[13]}$. As the pollution loading index may underestimate the pollution level of some heavy metals, such as a $\mathrm{Cd}$, it is only suitable for evaluating areas with higher concentrations and serious pollution of heavy metals.

In this study, the Hakanson potential ecological risk index was chosen to evaluate heavy metal pollution in tea plantation soils. This method can overcome the shortcomings of the single factor pollution index, the Nemerow comprehensive pollution index, the geoaccumulation index, and the pollution loading index. The Hakanson ecological risk index combines the ecological, environmental, and toxicological effects of heavy metals, and quantitatively describes the potential risk level of heavy metals. The assessment based on this index showed that among the seven heavy metals, $\mathrm{Cd}$ and $\mathrm{Hg}$ had higher ecological risk index values, with maximum values of 103.7 and 83.97, respectively. Statistical data showed that $\mathrm{Cd}$ and $\mathrm{Hg}$ were the dominant factors in the potential ecological risk in the tea plantation soils in southern Shaanxi. The contribution of $\mathrm{Cd}$ and $\mathrm{Hg}$ to the ecological risk was $35.5 \%$ and $46.5 \%$, respectively, and a total of $82 \%$ of the potential ecological risk was attributed to these two elements. The areas that exposed to a high level of $\mathrm{Cd}$ and $\mathrm{Hg}$ ecological risk were mainly distributed in the T2, T5, T6, T8, T12and T22 sampling areas. The high ecological risk index values could be attributed to several factors. For example, the T8 and T22 sites were adjacent to a highway, which increased the risk of potential heavy metal pollution from the vehicle exhaust. Meanwhile, the T2, T5, T6 and T12 sites were adjacent to mining enterprises, thus the dust deposition was inevitable in those sites. Therefore, the soil $\mathrm{Cd}$ and $\mathrm{Hg}$ concentrations were higher in these tea planting areas.

Numerous studies have shown that the correlations between heavy metals reflect their homologous relationship or combined pollution $^{[34-36]}$. In this study, correlation analysis of seven heavy metals in the soil samples revealed that $\mathrm{Cd}, \mathrm{Pb}, \mathrm{Hg}$ and $\mathrm{As}$ had a similar origin and caused combined pollution. In addition, $\mathrm{Cu}, \mathrm{Cr}$ 
and $\mathrm{Zn}$ in the tea plantation soils might also have a similar origin. These results are in agreement with previous studies. Xiao et al. $^{[37]}$ found that $\mathrm{Hg}, \mathrm{Pb}, \mathrm{Zn}, \mathrm{Cd}, \mathrm{Cr}$ and $\mathrm{Cu}$ in farmland soils in Kunshan, China may have a similar origin based on a correlation analysis of soil heavy metals. Sun et al. ${ }^{[28]}$ also found that the origins of $\mathrm{Cd}, \mathrm{Cu}, \mathrm{Pb}$, and $\mathrm{Zn}$ in soils in Shenyang, China are similar based on a correlation analysis of soil heavy metals. In addition, Xie et al. ${ }^{[38]}$ found that $\mathrm{Pb}, \mathrm{Zn}, \mathrm{Cu}, \mathrm{Ni}, \mathrm{Cr}$, As and $\mathrm{Cd}$ in soils samples collected from a pollution area in Taiyuan, China may have a similar origin.

The soil $\mathrm{pH}$ level reflects soil acidity, which can affect the form and activity of heavy metals. In this study, it was found that soil $\mathrm{pH}$ was significantly correlated with $\mathrm{Cd}$ and $\mathrm{Cu}$ concentrations $(p<0.01)$, and the soil $\mathrm{pH}$ was below 6 in the sampling areas. A previous study found that a low $\mathrm{pH}$ level can promote the dissolution and activation of heavy metals in soils ${ }^{[4]}$. One of the main requirements for the survival and growth of tea trees is acidic soil. In acidic conditions, soil $\mathrm{Cd}$ and $\mathrm{Cu}$ have high solubility, resulting in increased leaching and thus decreasing soil $\mathrm{Cd}$ and $\mathrm{Cu}$ concentrations. Moreover, the acidic soil environment may improve the bioavailability of $\mathrm{Cd}$ and $\mathrm{Cu}$ in tea plantation soils and thus increase the uptake and removal of these heavy metals by the shoots, which also decreases soil $\mathrm{Cd}$ and $\mathrm{Cu}$ concentrations.

It is worth noting that compared with other plants, tea trees are perennial evergreen plants with higher ability to enrich heavy metals in the soil and higher sensitivity to pollutants ${ }^{[15]}$. Therefore, long-term uptake and removal of soil $\mathrm{Cd}$ and $\mathrm{Cu}$ by tea can decrease soil $\mathrm{Cd}$ and $\mathrm{Cu}$ concentrations. But this may adversely affect the tea quality, resulting in an increased potential threat to human health. With increasing soil acidity (i.e., decline of soil $\mathrm{pH}$ ), the mobility and bioavailability of heavy metals in soils were significantly increased. A similar conclusion was drawn by Qin et al. ${ }^{[4]}$ in an assessment of heavy metal pollution in paddy soils from the northern Chengdu Plain. Higher soil acidity leads to easier uptake and accumulation of soil heavy metals by tea and greater threat to human health. Therefore, in acidic soils with a low level of heavy metal pollution, alkaline medium such as biochar can be appropriately applied to increase soil $\mathrm{pH}$ and in turn reduce the bioavailability of heavy metals, ultimately achieve safe production of tea.

It is strictly required to control the discharge of 'three wastes' into tea plantations that have been exposed to a high risk of $\mathrm{Cd}$ and $\mathrm{Hg}$ pollution. When establishing new tea plantations, the selection of locations should strictly follow the requirements of organic tea plantations and avoid pollution sources of heavy metals. It is not suitable to develop tea plantations in areas with a high background level of heavy metals (e.g., regions adjacent to industrial mining enterprises or with developed transportation). When these kinds of tea plantation have been established, a shelterbelt should be built to reduce the risk of heavy metal pollution caused by automobile exhaust emissions. When tea plantations are applied with large amounts of pesticides, fertilizers, and manures, more attention should be paid, as harmful elements such as $\mathrm{Cd}, \mathrm{Hg}$ and $\mathrm{Pb}$ might be introduced into soils. Thus fertilizers and pesticides should be applied properly based on soil and plant conditions to avoid unnecessary heavy metal pollution in tea plantations.

\section{Conclusions}

The mean concentrations of $\mathrm{Zn}, \mathrm{Hg}$, $\mathrm{As}$ and $\mathrm{Cd}$ in tea plantation soils of southern Shaanxi province were higher than the provincial background levels and showed different degrees of accumulation. The frequency of soil $\mathrm{Cd}$ concentration that exceeding the provincial background level was more than $41.2 \%$, and the maximum concentration was higher than the level II of China's Soil Environment Quality Standard. There were significant correlations between concentrations of most heavy metals tested in this study. The $\mathrm{Cd}$ had significant correlations with $\mathrm{Pb}, \mathrm{Hg}$ and As concentrations, and these four elements might also have a similar origin and could cause combined pollution in the study area. The $\mathrm{Cu}, \mathrm{Cr}$ and $\mathrm{Zn}$ also had significant correlations with each other, and these three elements might have a similar origin. The study area overall was at a low level of potential ecological risk for soil heavy metal pollution. The $\mathrm{Cd}$ and $\mathrm{Hg}$ were the two dominant elements in the soil potential ecological risk, and the $\mathrm{As}, \mathrm{Pb}, \mathrm{Cu}, \mathrm{Zn}$ and $\mathrm{Cr}$ contributed less to the soil potential ecological risk and generally had no effects on tea plantation soils.

\section{Acknowledgements}

This work was financially supported by Key Research and Development Program of Shaanxi Province, China (No. 2019NY-202), the Key Laboratory for Agricultural Environment, Ministry of Agriculture Open Foundation (No. 2015), Research Foundation of Education Bureau of Shaanxi Province, China (No. 19JS012) and the Shaanxi Province Key Laboratory of Bio-resources (2015SZS-15-04/09).

\section{[References]}

[1] Mugoša B, Đurović D, Nedović-Vuković M, Barjaktarović-Labović S, Vrvić M. Assessment of Ecological Risk of Heavy Metal Contamination in Coastal Municipalities of Montenegro. Int. J. Environ. Res. Public Health, 2016; 13: 393.

[2] Zhao Z P, Duan M, Yan S, Liu Z F, Wang Q, Fu J, et al. Effects of different fertilizations on fruit quality, yield and soil fertility in field-grown kiwifruit orchard. Int J Agric \& Biol Eng, 2017; 10(2): 163-172.

[3] Wang M E, Bai Y Y, Chen WP, Markert B, Peng C, Ouyang Z Y. A GIS technology based potential eco- risk assessment of metals in urban soils in Beijing, China. Environ Pollut, 2012; 161: 235-242.

[4] Qin Y S, Yu H, Feng W Q, Wang Z Y, Tu S H. Assessment on heavy metal pollution status in paddy soils in the northern Chengdu Plain and their potential ecological risk. Acta Ecologica Sinica, 2013; 33: 6335-6344.

[5] Mohammad N, Samar M, Alireza I. Levels of $\mathrm{Cu}, \mathrm{Zn}, \mathrm{Pb}$, and $\mathrm{Cd}$ in the leaves of the tea plant (Camellia sinensis) and in the soil of Gilan and Mazandaran farms of Iran. J Food Meas Charact, 2014; 8: 277-282.

[6] Yang L, Huang B, Hu W, Chen Y, Mao M. Assessment and source identification of trace metals in the soils of greenhouse vegetable production in eastern China, Ecotox Environ Safe, 2013; 97: 204-209.

[7] Khan S, Rehman S, Zeb Khan A, Amjad Khan M, Tahir Shah M. Soil and vegetables enrichment with heavy metals from geological sources in Gilgit, northern Pakistan. Ecotox Environ Safe, 2010; 73: 1820-1827.

[8] Cheraghi M, Lorestani B, Merrikhpour H, Rouniasi N. Heavy metal risk assessment for potatoes grown in overused phosphate-fertilized soils. Environ Monit Assess, 2013; 185: 1825-1831.

[9] Huang Z, Pan X D, Wu P G, Han J L, Chen Q. Heavy metals in vegetables and the health risk to population in Zhejiang, China. Food Control, 2014; 36: 248-252.

[10] Chen J D, Dai Q G, Xu X H, Zhong X C, Guo B W, Zheng C. Heavy metal contents and evaluation of farmland soil and wheat in typical area of Jiangsu Province. Acta Ecologica Sinica, 2012; 32: 3487-3496. (in Chinese)

[11] Yang J, Lv F D, Zhou J C, Song Y W, Li F. Health risk assessment of vegetables grown on the contaminated soils in Daye City of Hubei Province, China. Sustainability, 2017; 9: 2141;

[12] Suresh G, Sutharsan P, Ramasamy V, Venkatachalapathy R. Assessment of spatial distribution and potential ecological risk of the heavy metals in relation to granulometric contents of Veeranam lake sediments, India. 
Ecotox Environ Safe, 2012; 84: 117-124.

[13] Wang Y, Qiao M, Liu Y, Zhu Y. Health risk assessment of heavy metals in soils and vegetables from wastewater irrigated area, Beijing-Tianjin city cluster, China. J J Environ Sci., 2012; 24: 690-698.

[14] Mapanda F, Mangwayana E N, Giller K E, Nyamangara J. Uptake of heavy metals by vegetables irrigated using wastewater and the subsequent risks in Harare, Zimbabwe. Phys Chem Earth, Parts A/B/C, 2007; 32: 1399-1405.

[15] Zhou Y C, Li M S. Heavy metal contamination and transportation in soil-tea leaf-tea liquor system in two tea gardens of Guangxi. Journal of Agro-Environment Science, 2008; 27: 2151-2157. (in Chinese)

[16] Zhang J, Yang R, Chen R, Peng Y, Wen X, Gao L. Accumulation of heavy metals in tea leaves and potential health risk assessment: A case study from Pu'an County, Guizhou Province, China. Int. J. Environ. Res. Public Health, 2018; 15: 133.

[17] Lin D H, Tu Y Y, Zhu L Z. Concentrations and health risk of polycyclic aromatic hydrocarbons in tea. Food Chem Toxicol, 2005; 43: 41-48.

[18] Han W Y, Zhao F J, Shi Y Z, Ma L F, Ruan J Y. Scale and causes of lead contamination in Chinese tea. Environ Pollut, 2006; 139: 125-132.

[19] Zhang M K, Fang L P. Tea plantation-induced activation of soil heavy metals. Communications in Soil Science and Plant Analysis, 2007; 38: $11-12$.

[20] Guo H Y, Zhou W J, Zhang Y Z, Huang Y X, Zhou Q, Yan X. Content of soil heavy metals and characteristics of environmental quality in tea plantations of Changsha Bailitea zone. EnvironSci., 2008; 29: 2320-2326.

[21] Chen Z M, Ruan J Y, Cai D X, Zhang L J. Tri-dimension pollution chain in tea ecosystem and its control. Scientia Agricultura Sinica, 2007; 40: 948-958. (in Chinese)

[22] Huang S S, Liao Q L, Hua M, Wu X M, Bi K S, Yan C Y. Survey of heavy metal pollution and assessment of agricultural soil in Yang zhong district, Jiangsu Province, China. Chemosphere, 2007; 67: 2148-2155.

[23] Wu Y G, Jiang Z L, Luo Q. The accumulation and distribution of heavy metals in teas on both sides of highway. J Nanjing Forestry University (Natural Sciences Edition), 2002; 26: 39-42. (in Chinese)

[24] Shi Y Z, Han W Y, Ma L F, Ruan J Y. Influence factors on lead contents in Longjing Tea. J Agro-Environ Sci., 2004; 23: 899-903. (in Chinese)

[25] Michael Y, Chandravanshi B S, Wondimu T. Levels of essential and non-essential metal in leaves of the tea plant (Camelliasinensis L.) and soil of wush farms, Ethiopia. Food Chem, 2008; 107: 1236-1243.

[26] Lu R K. Analytical methods for soil and agro-chemistry. Beijing:
Chinese Agricultural Science and Technology Press, 2000. (in Chinese)

[27] Santos R W, Schmidt E Â C, Vieira I C, Costa G B, Rover T, Simioni C. The effect of different concentrations of copper and lead on the morphology and physiology of Hypnea musciform is cultivated in vitro: a comparative analysis. Protoplasma, 2015; 252(2): 1203-1215.

[28] Sun Y B, Zhou Q X, Xie X K, Liu R. Sources and risk assessment of heavy metal contamination of urban soils in typical regions of Shenyang, China. J Hazard Mater, 2010; 174: 455-462.

[29] Environmental Quality Standard for Soil. GB15618-2009. Beijing, Standards Press of China, 2009.

[30] Zhang J, Chen S Y, Deng H G, Wu A Q, Sun W B, Chen Y Y. Heavy metal concentrations and pollution assessment of riparian soils in Shandong Province. Acta Ecologica Sinica, 2012; 32: 3144-3153. (in Chinese)

[31] Marwa M E, Meharg A A, Rice M C. Risk assessment of potentially toxic elements in agricultural soils and maize tissues from selected districts in Tanzania. Sci Total Environ, 2012; 416: 180-186.

[32] Dai Y, Yang Z F, Zheng Y M. A review on the environmental behaviors and toxicity assessment of chromium in soil plant systems. Environ Sci., 2009; 30: 3432-3440.

[33] Ning X B, Xiang W H, Fang X, Yan W D, Deng X W. Heavy metal concentrations and pollution assessment of limestone forests in Huaxi district, Guiyang City. Acta Ecologica Sinica, 2009; 29: 2169-2177. (in Chinese)

[34] Atafar Z, Mesdaghinia A, Nouri J, Homaee M, Yunesian M, Ahmadimoghaddam M. Effect of fertilizer application on soil heavy metal concentration. Environ Monit Assess, 2010; 160: 83-89.

[35] Zhang H Z, Li H, Wang Z, Zhou L D. Accumulation characteristics of copper and cadmium in greenhouse vegetable soils in Tongzhou district of Beijing. Procedia Environ Sci., 2011; 10: 289-294.

[36] Galley F A, Lloyd O L. Grass and surface soils as monitors of atmospheric metal pollution in central Scotland. Water, Air and Soil Pollution, 1985; 24: 1-18.

[37] Xiao S S, Huang X J, Peng B Z, Pu Q J, Chen Y. Analysis of heavy metal pollution and assessment of its environmental effect in developed areas-case study in Kunshan of Suzhou city, Jiangsu Province. Resour Environ Yangtze Basin, 2007; 16: 674-679. (in Chinese)

[38] Xie W Y, Fan G S, Zhou H P, Xie J F, Guan C L. Access of heavy metals pollution of the sewage irrigation region in Taiyuan, China. J. Agro-Environ. Sci., 2011; 30: 1553-1560. (in Chinese) 